Revista IBERC

v. 3, n. 2, p. 289-304, maio/ago. 2020

www.responsabilidadecivil.org/revista-iberc

DOI: https://doi.org/10.37963/iberc.v3i2.126

\title{
ALGUNOS APUNTES SOBRE LA RESPONSABILIDAD CIVIL SANITARIA ANTE LA SITUACIÓN GENERADA POR EL COVID-19
}

\author{
ALGUMAS NOTAS SOBRE A RESPONSABILIDADE CIVIL EM SAÚDE EM FACE DA \\ SITUAÇÃO GERADA POR COVID-19
}

Manuel Ortiz Fernández ${ }^{\mathrm{i}}$

RESUMO: A situação gerada pelo COVID-19 (SARS-CoV-2) nos obriga a repensar o sistema de responsabilidade geral e, dentro dele, que se aplica ao campo da saúde. Nesse sentido, para determinar a adequação da conduta ao ad hoc lex artis é necessário refletir sobre o estado da ciência, a fim de determinar se o conhecimento permitiu agir em uma direção diferente. Do nosso ponto de vista, não é possível culpar esses atos que, não sendo adequados a partir de uma perspectiva ex post, apareceram como os certos com o conhecimento que foi tratado quando foram realizados. Em princípio, há argumentos suficientes para afirmar que atualmente não temos dados suficientes sobre a origem, as consequências e características essenciais do vírus e que, portanto, não estamos em um estágio de total dominação por parte da comunidade científica. Essa razão nos faz aplicar uma moderação ou limitação de responsabilidade a determinados atos e até mesmo a sua ausência. Além disso, temos mecanismos legais que podem ser invocados neste setor para prosseguir nesta linha e que serão brevemente discutidos.

Palavras-chave: COVID-19; Responsabilidade civil sanitária; Lex artis; Estado da ciência; Negligência.
RESUMEN: La situación generada por el COVID-19 (SARS-CoV-2) nos obliga a repensar el sistema de responsabilidad civil general y, dentro del mismo, el aplicable al ámbito sanitario. En este sentido, para determinar la adecuación de la conducta a la lex artis ad hoc se hace necesario reflexionar acerca del estado de la ciencia para determinar si los conocimientos permitían actuar en otro sentido. Desde nuestra perspectiva, no cabe reprochar aquellos actos que, no siendo los idóneos desde una perspectiva ex post, aparecían como los correctos con el conocimiento que se manejaba cuando se llevaron a cabo. Pues bien, en principio, existen argumentos suficientes para afirmar que no contamos, en la actualidad, con datos suficientes sobre el origen, las consecuencias y las características esenciales del virus y que, por tanto, no nos encontramos en un estadio de total dominio por parte de la comunidad científica. Este motivo provoca que podamos aplicar una moderación o limitación de responsabilidad sobre ciertos actos e, incluso, una ausencia de la misma. Además, contamos con mecanismos jurídicos que pueden invocarse en este sector para proceder en esta línea y que serán analizados brevemente.

Palabras clave: COVID-19; Responsabilidad civil sanitaria; Lex artis; Estado de la ciencia; Negligencia.

SUMÁRIO: Introducción. 1. El estado de la ciencia en el ámbito del COVID-19. 2. Posibles supuestos de responsabilidad sanitaria derivados del COVID-19. 3. Mecanismos jurídicos aplicables en España. 4. Principales conclusiones. Referencias.

\footnotetext{
i Profesor Ayudante de Derecho Civil de la Universidad Miguel Hernández de Elche. ORCID:
} https://orcid.org/0000-0001-7942-9907 


\section{INTRODUCCIÓN}

Al aproximarnos al tema relativo a la responsabilidad civil sanitaria debemos tener presente, en primer lugar, que nos encontramos ante una actividad profesional y que, por tanto, el criterio para determinar la adecuación de la conducta viene representado por la lex artis ad hoc ${ }^{1}$ o ley del oficio. En este sentido, supone una suerte de parámetro que determina la intervención que se presenta como correcta para el caso concreto, con la finalidad de comparar la misma con la que ejecutó el médico ${ }^{2}$. De este modo, se analiza el hecho ex post, desde la perspectiva de un espectador objetivo, para determinar si la operación se realizó cumpliendo con los estándares establecidos en el sector. Obviamente, para llevar a cabo este ejercicio es preciso atender al conocimiento que se tenía en el momento de producción del hecho. En otras palabras, se hace necesario recurrir al estado de la ciencia que, como veremos:

Engloba el contenido de la libre y diligente actuación profesional, esto es, abriga aquella serie de actitudes y conocimientos aplicables a su ejercicio cuya obtención y práctica conlleva que el profesional sea socialmente reconocido como tal ${ }^{3}$.

\footnotetext{
1 En este sentido, GUINOT BARONA, María. La responsabilidad extracontractual. In: Manual sobre Responsabilidad Sanitaria. Navarra: Aranzadi, 2009, p. 421 destaca, tras analizar la jurisprudencia del Tribunal Supremo, las siguientes características básicas de la lex artis:

(i) "Como tal lex implica una regla de medición de una conducta, a tenor de unos baremos, que valoran la citada conducta.

(ii) El objetivo o la función de este parámetro es valorar la corrección o no del resultado de la conducta médica enjuiciada, o su conformidad con la técnica normal requerida, esto es, que esa actuación médica sea adecuada o se corresponda con la generalidad de conductas profesionales ante casos análogos.

(iii) Se trata de una regla técnica -los principios o normas de la profesión médica en cuanto ciencia se proyectan al exterior a través de una técnica y según el arte personal de su autor- y profesional -el autor o afectado por la lex es un profesional de la medicina-.

(iv) Esta lex se caracteriza también por el objeto sobre que recae, que será una especie de acto (clase de intervención, medios asistenciales, estado del enfermo, gravedad o no, dificultad de ejecución).

(v) Es una lex ad hoc, que se concreta para cada acto médico o presupuesto de su aplicación siendo quizá esta la nota que individualiza a la lex artis médica, pues así como en toda profesión rige una lex artis que condiciona la corrección de su ejercicio, en la médica esa lex, aunque tenga un sentido general, responde a las peculiaridades de cada acto, en donde influirán en un sentido u otro los factores anteriormente indicados».

2 En este punto, conviene señalar que, desde nuestra perspectiva, encontramos dos tipos de lex artis sanitaria. De un lado, la derivada de la propia intervención, esto es, de la adecuación de la praxis empleada para estos fines. De otro, la referida al consentimiento informado y a los deberes que impone en este ámbito nuestra legislación. Sin embargo, al margen de alguna referencia, esta última no va a ser analizada en profundidad en esta obra por exceder de nuestra finalidad.

${ }^{3}$ Como destaca DE LAS HERAS GARCÍA, Manuel Ángel. Lex Artis, Onus Probandi y responsabilidad médica. Revista jurídica de la Región de Murcia. $n^{\circ} 36$, p. 17-19, 2005, «A pesar de que esta propia voz profesional- constituye un noción metajurídica, con varias significaciones, arrancando del sentido gramatical de profesión y en su acepción eminentemente sociológica equivale a ostentar determinados conocimientos en una concreta materia que llevan aparejados una cualificación profesional (plasmada, a su vez, en una certificación o título), constituyendo lo más característico de las profesiones liberales -como es la médica- la autonomía o independencia en su ejercicio con sometimiento, como criterio rector, a esta denominada lex artis con carácter prácticamente exclusivo. Diversos han sido los conatos en orden a definir esta lex (identificada, por lo general, con aquella regla de la técnica de actuación de la profesión que se trate) la cual viene referida, en último término, a aquella esfera de autonomía profesional cuya regulación exclusivamente incumbe a sus miembros (reputados artífices o profesionales) que, a la postre, son los encargados de encarnar un modelo de conducta representado por las reglas o técnicas específicas de un concreto arte u oficio incumbiendo, por ende, el establecimiento de tal lex en Medicina a la propia profesión médica. Cabe mantener que las leges artium de cada profesión son aquéllas que gobiernan la actuación de los profesionales que consideremos, toda vez que el genérico modelo de conducta del buen padre de familia se
} 
Desde esta perspectiva, tenemos que estudiar la situación generada por el COVID-19 (SARS-CoV-2) y las nefastas consecuencias que ha provocado para tratar de establecer si el estado de la ciencia es suficiente para exigir un determinado tipo de conducta a los profesionales de la salud o si, por el contrario, este extremo no se produce y, por tanto, podemos recurrir a una limitación de responsabilidad o, incluso, a una total exención de la misma. No obstante, téngase en cuenta que la respuesta a estas cuestiones no es sencilla y no se encuentra exenta de discusión. No podemos perder de vista que pueden esgrimirse argumentos en ambos sentidos y que existe fundamento para defender una y otra posición. Las reflexiones que adoptemos, por tanto, representan una forma particular de analizar la realidad actual y sin ánimo de establecer verdades generales.

Como es sabido, este virus se ha cobrado, hasta el momento de escribir estas líneas, más de cuatrocientos setenta mil fallecidos y la cifra de contagios supera los nueve millones. Asimismo, ha conllevado que en muchos estados se decretasen estados excepcionales que incluían, entre otras, medidas restrictivas de la libertad deambulatoria. De esta forma, las actividades económicas se vieron paralizadas durante un espacio prolongado de tiempo y, como consecuencia, se ha producido un gran impacto en las economías nacionales que se han visto mermadas. Sin embargo, aunque en la actualidad se está volviendo a retomar la "nueva normalidad" en muchos de los países, están surgiendo nuevos rebrotes por lo que parece que, lejos de finalizar esta situación, se mantendrá más de lo que se esperaba. Además, a pesar de los indudables avances, no contamos con una vacuna o medicamento que sea eficaz para combatir sus efectos. De hecho, ni se conoce con certeza el propio origen del coronavirus.

\section{EL ESTADO DE LA CIENCIA EN EL ÁMBITO DEL COVID-19}

Como hemos indicado, la lex artis sanitaria se ha vinculado al ejercicio de la técnica, en suma, a la praxis adecuada. No obstante, para determinar el contenido de la misma resulta esencial concretar el estado de la ciencia del momento de producción del hecho que se pretende imputar. No puede obviarse que las obligaciones de los profesionales variarán en función de este último, ya que no es posible exigir una conducta que no podía preverse en el momento de producirse. En este sentido, si no se conocía la existencia del COVID-19 ni sus causas, efectos o procedimientos de curación, no parece adecuado que deba reprocharse la actividad de los médicos. Este razonamiento es aplicable para todos aquellos supuestos en los que, por el propio desconocimiento, se aplicó un tratamiento que no era, desde una perspectiva ex post, el idóneo.

Para aclarar estas cuestiones, podemos preguntarnos acerca de la interpretación ofrecida a otras enfermedades que eran desconocidas en el momento de generar daños. En esencia, vamos a tratar de estudiar brevemente el razonamiento que se aplicó para tratar de determinar si el estado de la ciencia permitía tener constancia de estos extremos. Por ejemplo,

caracteriza, precisamente, por la negación de todo conocimiento técnico, su naturaleza no profesional o especializada». 
podemos traer a colación los contagios producidos por VHC (hepatitis C). A este respecto, la doctrina 4 aludió a estas disquisiciones, señalando que:

\begin{abstract}
La comunidad científica internacional conocía, desde 1975, la existencia de un virus causante de la hepatitis que no era ni A ni B, así como lo es que no fue hasta 1989 cuando pudo identificarse el virus de la hepatitis C (VHC) y, por consiguiente, pudo desarrollarse el primer test de detección del virus en cuestión. También es cierto que en el Estado español, la obligación de analizar la presencia de $\mathrm{VHC}$ en las donaciones de sangre se impuso en octubre de 1990.
\end{abstract}

Igualmente, la jurisprudencia se manifestó en estos términos ${ }^{5}$. Por su parte, también la transmisión de VIH (virus de la inmunodeficiencia humana) planteó equivalentes problemáticas, sobre lo cual se indicó que «Los avances de la ciencia no han sido paralelos en cuanto a técnicas de control de hemoderivados y de transfusiones sanguíneas, por lo que su tratamiento debe hacerse por separado ${ }^{6} »$. El Tribunal Supremo ${ }^{7}$ destacó en diversas sentencias que:

Hasta el año 1985 el estado de los conocimientos de la técnica no permitía detectar la existencia de VIH en sangre, por lo que todas las transfusiones de plasma, efectuadas con anterioridad a dicho año 1985, en que se hubiera podido inocular el indicado virus, no generan responsabilidad patrimonial de la Administración sanitaria por no ser la lesión causada antijurídica.

De esta forma, en el ámbito de una situación extraordinaria y debido a la ausencia de certezas acerca de la misma es posible que no se pueda actuar de forma correcta o totalmente precisa y que esto último se realice con algún error fruto de la ausencia de certezas propias del momento ${ }^{8}$. En cuanto al COVID-19, debemos plantearnos si nos encontramos ante uno de estos casos. Pues bien, si atendemos a la alocución de apertura del Director General de la Organización Mundial de la Salud en la rueda de prensa sobre el COVID-19 celebrada el 11 de marzo de $2020^{9}$, en la que se declaró la pandemia, no parece inferirse que podía, de algún modo, preverse ni la existencia del virus ni su evolución. De hecho, en la fecha citada, el número de casos de COVID-19 fuera de China ya se había multiplicado por trece y el número de países

${ }^{4}$ En este sentido, vid. BLAS ORBÁN, Carmen. Contagio transfusional de VHC. Reflexiones sobre la previsibilidad del daño. DS. v. 16/2008, p.181-182, 2008.

${ }^{5}$ Vid., entre otras, las SSTS n 9345/1996 Sala Tercera 17 abril 2001 (RJ 4215), n 6972/1997 Sala Tercera 1 noviembre 2001 (RJ 10098), $\mathrm{n}^{\circ}$ 7126/1997 Sala Tercera 22 noviembre 2001 (RJ 2002/5432), $\mathrm{n}^{\circ}$ 5446/2005 Sala Tercera 8 octubre 2010 (RJ 7214).

${ }^{6}$ MUGA MUÑOZ, José Luis. La responsabilidad patrimonial de las administraciones publicas por el contagio de sida. RAP. $\mathrm{n}^{\circ} 136$, p. 287, 1995.

7 Vid., entre otras, las SSTS n 12/2002 Sala Tercera 29 noviembre 2002 (RJ 2003\283), n 2911/2001 Sala Tercera 10 diciembre 2004 (RJ 2005\473), n 172/2005 Sala Tercera 13 junio 2006 (RJ 3469).

${ }^{8}$ Es posible plantear otros supuestos de responsabilidad en este ámbito. Por ejemplo, por integrar la inteligencia artificial para mejorar los tratamientos o por infecciones producidas en el ámbito de la estructura sanitaria. En este sentido, vid. DA GUIA SILVA, Rodrigo/NOGAROLI, Rafaella. Utilização da inteligência artificial na análise diagnóstica da COVID-19: benefícios, riscos e repercussões sobre a responsabilidade civil do médico. In: RÊGO MONTEIRO FILHO, Carlos Edison Do/ROSENVALD, Nelson/DENSA, Roberta (coord.). Coronavírus e responsabilidade civil: impactos contratuais e extracontratuais. Brasil: Editora Foco, SP, 2020, p. 293-300; GIOVA, Stefania. Infezione da COVID-19 e responsabilità della struttura sanitaria. AJI. n० 12 bis, p. 502-511, may. 2020.

${ }^{9}$ Disponible en:

https://www.who.int/es/dg/speeches/detail/who-director-general-s-opening-remarks-at-the-media-briefingon-covid-19---11-march-2020 (fecha de última consulta 29.04.2020). 
afectados se había triplicado. Igualmente, el Real Decreto 463/2020, de 14 de marzo, por el que se declara el estado de alarma para la gestión de la situación de crisis sanitaria ocasionada por el COVID-19, pone de relieve la concurrencia de circunstancias extraordinarias que constituyen, sin duda, "una crisis sanitaria sin precedentes y de enorme magnitud tanto por el muy elevado número de ciudadanos afectados como por el extraordinario riesgo para sus derechos».

Asimismo, la doctrina científica también apunta a que se trata de una enfermedad nueva e inédita. En este sentido, algunos autores ${ }^{10}$ destacan que estamos ante una «infección causada por un nuevo coronavirus» que ha dado lugar a la declaración de la Organización Mundial de la Salud sobre esta "emergencia de salud pública de interés internacional", «considerada así de acuerdo con la sugerencia de un grupo de expertos y con los lineamientos del Reglamento Sanitario Internacional (RSI, 2005)». Por su parte, otros autores ${ }^{11}$ indican que los pacientes presentaron «diagnósticos de neumonía de etiología no conocida» que representó «nueva amenaza».

A pesar de ello, también es posible concluir en un sentido contrario. Máxime si atendemos a que en marzo de 2018 la Organización Mundial de la Salud ya incluyó la «enfermedad X» (disease $X$ ) en su listado de patógenos infecciosos. De hecho, se comenzó a referir la posibilidad de que se produjera una pandemia y se instó a los estados miembros a adoptar las medidas necesarias para estar preparados ante una posible emergencia causada por un patógeno desconocido. Además, tal y como apuntan muchas fuentes con el COVID-19, el origen de esta enfermedad se hizo residir en el contacto de las personas con los animales. En suma, se indicó que se desarrollaría a través de un mecanismo de transmisión zoonótica. Igualmente, existen voces que aluden a la posibilidad de que el COVID-19 sea un virus creado por los humanos en los laboratorios.

Sea como fuere, entendemos que existen más evidencias para afirmar que el estado de la ciencia no permitió prever la naturaleza e impacto del COVID-19 y que, por tanto, no cabe exigir que los profesionales llevaran a cabo una actuación totalmente diligente pues, sencillamente, no era posible. Ello no es óbice para señalar que, quizás, la gestión de esta crisis no ha sido la idónea y que, de haber tomado otras decisiones más acertadas, el impacto hubiera sido menor. No obstante, consideramos que este hecho no es imputable a los sanitarios. Obviamente, tras esta pandemia el conocimiento y la preparación debe ser mayor y, por tanto, de ocurrir otra en el futuro, el nivel de diligencia aumentará sin que quepa invocar ciertas cuestiones como eximentes de responsabilidad.

Todo lo anterior, nos lleva a concluir que, en principio, debido al estado de la ciencia, ciertas conductas no representan una fuente de responsabilidad. No obstante, es necesario establecer cuándo no será posible acudir a este razonamiento para excepcionar estos deberes. En otras palabras, se trata de determinar el momento a partir del cual el estado de la ciencia

${ }^{10}$ RAMOS, Celso. Covid-19: la nueva enfermedad causada por un coronavirus. Salud pública de México. v. 62/2020, p. 226, 2020.

11 KOURY GONZÁLEZ, Juan Miguel/HIRSCHHAUT, Miguel. Reseña histórica del COVID-19. ¿Cómo y por qué llegamos a esta pandemia?. Acta odontológica venezolana. v. 58/2020, p. 3, 2020. 
permite conocer, al menos, las características y consecuencias fundamentales del COVID-19, pues, tras el mismo, no cabrá recurrir a la ausencia de conocimiento para fundamentar una exención de responsabilidad. Esta tarea es realmente compleja por varios motivos. Por un lado, porque es posible que los avances en la medicina resulten, posteriormente, revocados por otros estudios. No puede obviarse que estamos ante una ciencia no exacta que funciona a través del método heurístico, esto es, del ensayo y error. En este sentido, destaca de una forma muy acertada Rosenvald ${ }^{12}$ que:

\begin{abstract}
Medicina, enfim, não é uma ciência tão exata como gostaríamos que fosse. As formas de abordagem e terapêutica diante do mesmo problema variam enormemente, dependendo do médico. Além do mais, conforme frisamos, os organismos humanos nem sempre respondem do mesmo modo. Quanto mais complexas forem as variáveis, mais difícil será prever, com exatidão, o que pode acontecer. Não raro, frente a um mesmo dilema técnico, médicos divergem frontalmente. Não é simples nem fácil, nesse contexto, solucionar judicialmente essas demandas, sobretudo se tivermos em conta o óbvio fato que o juiz não dispõe, pessoalmente, de formação profissional na área médica.
\end{abstract}

Las hipótesis que surgen están sometidas a verificación y esta última puede rechazar las certezas que se manejaban en un primer momento. De hecho, algo similar está ocurriendo con el COVID-19 tanto en la búsqueda de una vacuna como en su propio origen o consecuencias.

Por otro lado, porque no es sencillo determinar el momento en el que el estado de la ciencia es suficiente en un ámbito concreto. En este sentido, puede plantearse que esto último se produce cuando se dispone de una cura o tratamiento. Siguiendo este razonamiento, todavía no se habría producido tal circunstancia. Sin embargo, no queda claro que deba ser este el hecho determinante. Bien podría pensarse que basta con saber aquellos aspectos fundamentales de la enfermedad de que se trate. Asimismo, no puede obviarse que los virus evolucionan constantemente y que muchas de las vacunas se adaptan anualmente para hacer frente a las variaciones (como ocurre, por ejemplo, con la gripe).

Desde nuestra perspectiva, el nivel adecuado del estado de la ciencia sobre una patología se alcanza cuando se conoce su origen, sus causas y consecuencias principales y cuando, aun sin disponer de un tratamiento concreto totalmente eficaz, se está trabajando de forma avanzada en el mismo. En la actualidad, parece que no hemos logrado alcanzar tal estadio y que nos movemos en una fase intermedia, ya que a pesar de que se está preparando una vacuna, no se puede asegurar que la misma sea la correcta. Además, continúan apareciendo estudios que desmienten muchas de las hipótesis que se manejaban acerca de la procedencia misma del virus.

En otro orden de cosas, conviene anudar una reflexión a todo lo anterior. Como resulta evidente, el avance de la ciencia y de la medicina depende, en gran medida, de las aportaciones que las autoridades destinen a tales fines. Son de sobra conocidas las peculiares circunstancias económicas de España, máxime desde la crisis financiera de 2008. Este hecho se agrava más,

12 ROSENVALD, Nelson. Responsabilidade civil na área médica. AJI. nº 8, p. 377, feb. 2018. 
si cabe, por las devastadoras consecuencias del COVID-19 que ha paralizado la actividad de muchos países. Por lo tanto, los medios que se han puesto a disposición de los investigadores y profesionales en este ámbito han sido muy reducidos y no han permitido una mejor gestión.

Sin embargo, no cabe acudir al razonamiento anterior para justificar todas aquellas intervenciones llevadas a cabo sin respetar ningún deber profesional. De esta suerte, no es posible invocar el estado de la ciencia para prescindir de todas las obligaciones que prevé nuestra legislación actual. Imagínese, por ejemplo, que el médico entiende que, a pesar de la voluntad del usuario, lo más adecuado es aplicar una técnica que ha sido rechazada por la comunidad científica. Obviamente, ello no quiere decir que la rápida expansión del virus impida la aplicación de determinadas medidas previstas en nuestro ordenamiento ${ }^{13}$, pero, en tal caso, tendremos que encontrar una base habilitadora.

\section{POSIBLES SUPUESTOS DE RESPONSABILIDAD SANITARIA DERIVADOS DEL COVID-19}

En este punto, debemos preguntarnos acerca de algunos supuestos que podemos encontrarnos en la práctica en los que, a pesar de suponer una actividad negligente por parte del profesional, sin embargo, por las circunstancias excepciones producidas por el coronavirus, cabría aplicar limitaciones o exenciones de responsabilidad. Si se repara con detenimiento, nos estamos refiriendo a casos en los que, si bien se produce un daño al paciente, el mismo no debe ser resarcido porque, de algún modo, este último tiene el deber jurídico de soportarlo o, si se quiere, porque no contamos con suficientes argumentos para imputarlos al sujeto activo. En realidad, no es una solución que pueda reputarse de totalmente justa, pero con la adopción de la que se presenta como alternativa, quizás, se alcanzarían resultados que todavía lo serían menos. Asimismo, con carácter previo, conviene tener en cuenta que, si el centro es público, nos encontraremos ante la responsabilidad patrimonial de las administraciones públicas y, en consecuencia, se aplicará el Derecho administrativo y la causa se ventilará ante los tribunales contencioso-administrativos. Por el contrario, si la naturaleza del mismo es privada, la jurisdicción competente será la civil e igualmente acudiremos al Derecho privado. En estas líneas nos vamos a referir a las distintas cuestiones que surgen desde el prisma del Derecho civil, por lo que las conclusiones que adoptemos no son extrapolables a otras ramas jurídicas por las especialidades que tienen.

Si nos adentramos en el análisis de los supuestos concretos, podemos imaginar, por ejemplo, que un sanitario emplee una técnica que, siendo la recomendada por la comunidad científica del momento, cause una serie de daños al paciente por no resultar la adecuada. En este escenario, entendemos que el estado de la ciencia no permite actuar de otro modo, ya que

${ }^{13}$ En este sentido, ALVENTOSA DEL RíO, Josefina. Salud y Derecho en tiempos del COVID-19. AJI. $\mathrm{n}^{\circ} 12$ bis, p. 117, may. 2020 señala que existen normas que avalan la toma de estas decisiones cuya finalidad es contener la expansión del virus y preservar la salud de la ciudadanía y que estas medidas «han tenido un resultado que prudentemente se puede calificar de positivo en cuanto han ido paliando la extensión de la epidemia en nuestro país, preservando con ello la vida y la salud de las personas y, por ende, estos derechos que tan esenciales son al ser humano». 
ha recurrido al conocimiento con el que se cuenta y, desde nuestra perspectiva, no es adecuado que se reproche este hecho. Cuestión distinta es que el médico, alejándose de las indicaciones de los protocolos, recurra a una intervención o procedimiento concreto. En tal caso, sí estaríamos ante un ilícito civil que tendría que ir acompañado de un resarcimiento al paciente. Sea como fuere, lo cierto es que en una situación de incertidumbre como la actual, incluso podría producirse la paradoja que la intuición profesional de un sanitario sea distinta a la seguida por la mayoría de sus homólogos y, sin embargo, resulte ser la correcta. Además, no puede obviarse que los avances se producen a un ritmo demoledor y que, en ocasiones, exige una continua adaptación y actualización que no siempre puede realizarse.

Por otro lado, es bastante plausible ( $\mathrm{y}$, de hecho, así ha ocurrido) que un usuario acuda a un centro con una patología determinada y que, por el transcurso de un espacio prolongado de tiempo en contacto con otros pacientes que estén afectados por el virus u otros motivos, resulte finalmente contagiado de COVID-19. No obstante, al menos con carácter general, en estas situaciones sería responsable el propio hospital y no los distintos profesionales de la salud. Igualmente, cabe reflexionar sobre aquellas situaciones en los que no es posible intervenir a un usuario por no disponer del personal suficiente. Parece lógico pensar que no se debe exigir a los centros una preparación total para este tipo de escenarios, máxime, porque la pandemia ocurrió de forma inesperada y, en cierta forma, imprevisible. Además, quizás supondría una exigencia desproporcionada de recursos destinados a estos fines. Esta conclusión puede variar si estamos ante un hospital público, ya que, en dichos casos, no queda tan claro que deba aplicarse una limitación de responsabilidad por cuanto la inversión ha de ser mucho mayor.

En otro orden de cosas, podemos referirnos a ciertos hechos en los que resultaría afectado el derecho al consentimiento informado de los pacientes. El mismo está formado por dos facultades que se encuentran íntimamente vinculadas, a saber, la información previa y el posterior consentimiento. En esencia, conlleva que el usuario tiene derecho a conocer todos aquellos extremos relevantes relacionados con la intervención de que se trate y que, tras contar con estos datos, podrá decidir lo que estime oportuno ${ }^{14}$. Se trata, pues, de una manifestación del derecho de autodeterminación por cuanto supone que la persona escoja de una forma libre, voluntaria y consciente entre las opciones vitales que se le presentan, debiendo ser respetada su voluntad. Si se observa con detenimiento, estamos ante una atribución de deberes al profesional distinta a la impuesta por la que podemos denominar lex artis tradicional que se refiere, como es de sobra conocido, a la adecuación a los estándares establecidos por la comunidad científica en la ejecución de la operación. Por este motivo, consideramos que lo más adecuado es diferenciar entre ambos tipos de lex artis, de tal suerte que a la ya citada tenemos que sumar la lex artis referida a las obligaciones que nuestra legislación impone en materia de consentimiento informado. La norma de referencia en este campo es la Ley 41/2002, de 14 de noviembre, básica

${ }^{14}$ De una forma muy acertada, destaca BARCELÓ DOMÉNECH, Javier. Consentimiento informado y responsabilidad médica. AJI. $n^{\circ} 8$, p. 281, feb. 2018 que «El fundamento del consentimiento informado está en la idea de autonomía individual del paciente y el estímulo a la toma de decisiones racionales. Se trata de decidir con el paciente y no por él desde la superioridad del criterio médico». 
reguladora de la autonomía del paciente y de derechos y obligaciones en materia de información y documentación clínica.

En cuanto a su naturaleza jurídica, de una forma muy resumida, podemos señalar que estamos ante un derecho de configuración legal con implicaciones constitucionales en tanto en cuanto se encuentra ligado a ciertos derechos fundamentales. A pesar de que, en ciertas situaciones (como la que hemos analizado anteriormente) esta vinculación bien pueda realizarse con otros derechos, entendemos que se encuentra ligado, más directamente, con la integridad física y moral (art. $15 \mathrm{CE}^{15}$ ). De hecho, en estos términos se manifestó el propio Tribunal Constitucional, en la STC no 37/2011 28 marzo 2011 (RTC 37). Sin embargo, no puede pensarse que estamos ante facultades absolutas. Muy al contrario, la citada Ley 41/2002 prevé una serie de límites y excepciones que pueden invocarse en este ámbito. Asimismo, en el escenario generado por el COVID-19 también se puede esgrimir el estado de la ciencia en este campo, así como otras disposiciones como la Ley 33/2011, de 4 de octubre, General de Salud Pública o el Real Decreto 463/2020, de 14 de marzo, por el que se declara el estado de alarma para la gestión de la situación de crisis sanitaria ocasionada por el COVID-19, si bien esta última hasta la finalización de dicho estado (sucesivamente prorrogado) que se produjo el 21 de junio.

En este punto, debemos tratar de reflexionar acerca un caso que pueda quedar englobado en este ámbito. Como es sabido, una de las medidas que ha conllevado el coronavirus ha sido el confinamiento de toda la población para evitar la propagación del mismo. En este sentido, si un paciente se encontraba obteniendo asistencia médica y se le detectó el virus, es factible que se restringiera su libertad y que se recluyera a un lugar aislado y sin contagios, incluso en contra de su voluntad. Pues bien, ¿qué ocurriría si se demuestra que, en realidad, no estaba infectado? ¿Estaríamos ante una conducta negligente? Como se observa, esto último afecta, además, al derecho fundamental a la libertad deambulatoria (art. $19 \mathrm{CE}$ ), con la especial protección que implica y con el acceso al recurso de amparo. Si avanzamos un poco más, ¿qué pasaría si el usuario se contagió de COVID-19 por dicha decisión equivocada? De nuevo, la respuesta no es sencilla y pueden esgrimirse argumentos en ambos sentidos. Sin ánimo de establecer verdades generales, entendemos que la celeridad del momento y la necesidad de adoptar decisiones sin contar con el tiempo necesario para reposarlas puede conllevar, sin duda, errores y diagnósticos precipitados. Sin embargo, consideramos que no se debe hacer residir la responsabilidad en los profesionales en estas condiciones, pues, sencillamente, no existían demasiadas alternativas en atención al estado de la ciencia.

Por otro lado, también podemos ubicar otros ejemplos de actos que, siendo negligentes, no deberían ir acompañados de responsabilidad, como los derivados de la prestación de una información errónea. Imaginemos que, por ejemplo, se comunica al usuario que se encuentra afectado por el COVID-19 y, en realidad, no lo está o, al contrario, esto es, que se le indique que no tiene ningún problema cuando, sin embargo, tiene el virus en su organismo. De hecho, en este último supuesto las consecuencias pueden afectar a terceras personas en la

${ }^{15}$ Para más información, vid. GÓMEZ ABEJA, Laura. Consentimiento informado y derechos fundamentales. Revista Europea de Derechos Fundamentales. n 18, p. 275-306, 2011. 
medida en que, al no tomar las precauciones y las medidas de seguridad necesarias como consecuencia de la errónea información, contagie a familiares o a amigos. No obstante, lo cierto es que la prueba de este extremo no es sencilla, ya que tendría que demostrar que desarrolló la enfermedad por esta circunstancia y no por otra. Por último, existen otros casos en los que se conculcaría el propio consentimiento legitimador de la intervención cuando el profesional aplica técnicas o procedimientos sin atender a la voluntad del paciente e, incluso, oponiéndose a la misma (con independencia de su corrección técnica y del posible beneficio para su salud).

\section{MECANISMOS JURÍDICOS APLICABLES EN ESPAÑA}

Tras estos breves apuntes, vamos a citar algunos de los mecanismos jurídicos previstos en el ordenamiento español y que cabría invocar en el ámbito del COVID-19. Sin entrar en disquisiciones acerca de la distinción entre los sectores contractual ${ }^{16}$ y extracontractual (que entendemos superada en la actualidad por la unidad de culpas civil), en el primero podemos encontrar varias posibilidades que tendrían como efecto fundamental la rescisión del negocio, la modificación de determinadas cláusulas o la aplicación de eximentes (o moderadores) de responsabilidad. Por citar algunos, vid. la fuerza mayor, el caso fortuito o el cambio sobrevenido de las circunstancias (expresado, fundamentalmente, a través de la cláusula rebus sic stantibus).

En cuanto a los dos primeros supuestos, baste con señalar que la fuerza mayor siempre elimina la responsabilidad, ya que se concreta en una situación en la que ocurre un hecho que no pudo preverse (ni por el más diligente de los hombres) o que, de haberse podido prever, era inevitable e irresistible. Por su parte, el caso fortuito también exonera de responsabilidad (generalmente) y supone un hecho imprevisible, aplicando el cuidado y la diligencia debidos. Por lo tanto, nos movemos ante un caso fortuito si la persona diligente no pudo evitar el resultado a pesar de aplicar la atención que exige el supuesto. La diferencia entre ambas radica en la posibilidad o no de evitar el daño ${ }^{17}$. Así, en la fuerza mayor el resultado es inevitable en cualquier caso y ante cualquier conducta del agente. Por otro lado, en el caso fortuito se podría impedir la producción del daño con un nivel de diligencia superior al normal (medio). Sin embargo, se entiende que no se puede exigir tal nivel de cuidado a una persona y, por tanto, no se le hace responsable. Si se repara con detenimiento, en los dos casos existe un hecho ajeno al comportamiento del sujeto pasivo, lo que provoca que no pueda atribuirse el resultado al mismo.

Por su parte, debemos referirnos al cambio sobrevenido de las circunstancias esenciales que justificaron su celebración. En este contexto, las peculiares características que

\footnotetext{
${ }^{16}$ Para más información, vid. DE OLVEIRA MILAGRES, Marcelo. Os efeitos do coronavírus (covid-19) e a irreversibilidade não imputável do incumprimento contratual. In: RÊGO MONTEIRO FILHO, Carlos Edison Do/ROSENVALD, Nelson/DENSA, Roberta (coord.). Coronavírus e responsabilidade civil: impactos contratuais e extracontratuais. Brasil: Editora Foco, SP, 2020, p. 47-54.

${ }_{17}$ Asimismo, en algún caso, el Tribunal Supremo ha recurrido a la teoría que diferencia entre los sentidos subjetivo y objetivo para determinar si estamos ante un caso fortuito o ante fuerza mayor. El primero, viene referido a la ausencia de culpa e intención de causar un daño. El segundo, a la existencia de un elemento sobrevenido que altera el curso causal normal.
} 
rodean al supuesto provocan que sea especialmente gravoso para una de las partes el cumplimiento de las prestaciones a las que se vinculó. Como hemos destacado, esta facultad se canaliza a través de la denominada cláusula rebus sic stantibus, cuyo origen se vinculó a los contratos de tracto sucesivo. El efecto que se produce con este tipo de cláusula es, fundamentalmente, la modificación de los términos en que se fijaron las prestaciones, pudiendo dar lugar, en los casos extremos, a la rescisión de la relación obligacional. Como destaca parte de la doctrina ${ }^{18}$ «El Derecho moderno es un proceso de cambio y de adaptación que debe estar engrasado a través de mecanismos que permitan esa adaptación» y la «figura que mejor ejemplifica dicho mecanismo es la cláusula rebus sic stantibus, que está directamente conectada con esa perspectiva del Derecho de adaptación al cambio de circunstancias para la obtención soluciones rápidas».

No obstante, lo cierto es que la jurisprudencia ha ido variando y no siempre se ha mostrado favorable a la cláusula rebus sic stantibus ${ }^{19}$. Los últimos pronunciamientos hacen referencia a la necesidad de que exista una modificación imprevisible o inevitable de las circunstancias, cuyos riesgos no puedan subsumirse en los derivados del propio contrato. De esta forma, no cabe alegar una situación de crisis económica para fundamentar una alteración del negocio. A modo de ejemplo, la STS n 452/2019 18 julio 2019 (RJ 3010) ${ }^{20}$ recuerda que:

La alteración de las circunstancias que puede provocar la modificación o, en último término, la resolución de un contrato, ha de ser de tal magnitud que incremente de modo significativo el riesgo de frustración de la propia finalidad del contrato. Y por supuesto, es preciso que tales circunstancias sobrevenidas fueran totalmente imprevisibles para los contratantes.

Además, añade que si las partes han asumido expresa o implícitamente el riesgo de que una circunstancia aconteciera o debieron asumirlo porque, en virtud de las circunstancias y/o naturaleza del contrato, «tal riesgo era razonablemente previsible, no es posible apreciar la alteración sobrevenida que, por definición, implica lo no asunción del riesgo».

En contra de la vigencia de la cláusula rebus sic stantibus en los contratos temporales se manifiesta la reciente STS n 156/2020 6 marzo 2020 (RJ 879) que, sin rechazar de plano su aplicación, la limita a los supuestos en los que se produzca un hecho que afecte al negocio y no pueda quedar amparado en el riesgo propio del mismo. En palabras del tribunal:

\footnotetext{
18 ORDUÑA MORENO, Francisco Javier. Webinar COVID-19: La rebus en tiempos de crisis. vLex. $\mathrm{n}^{\circ} 2020$, disponible en: https://libros-revistas-derecho.vlex.es (fecha de última consulta 08.05.2020). Para más información sobre esta cláusula, vid. ORDUÑA MORENO, Francisco Javier/MARTíNEZ VELENCOSO, Luz María. La moderna configuración de la cláusula Rebus Sic Stantibus. Desarrollo de la nueva doctrina jurisprudencial aplicable y Derecho comparado. Madrid: Civitas, 2017.

${ }^{19}$ Esta evolución puede observarse, entre otras, en las SSTS n 1059/2000 17 noviembre 2000 (RJ 9343), $n^{\circ}$ 1234/2001 28 diciembre 2001 (RJ 2002l1650), n 820/2013 17 enero 2013 (RJ 1819), n 333/2014 30 junio 2014 (RJ 3526), n² 227/2015 30 abril 2015 (RJ 2019).

Tampoco la aplicación de esta cláusula ha sido pacífica en el resto de tribunales. A modo de ejemplo, vid. SAP A Coruña 18 febrero 2013 (JUR 127710), SAP Granada 17 enero 2014 (JUR 99088), SAP Baleares 17 octubre 2014 (JUR 2015\5552), SJ de lo Mercantil Murcia n² 23 enero 2018 (AC 852).

${ }^{20}$ En igual sentido, vid. SSTS n 5/2019 9 enero 2019 (RJ 5), n 19/2019 15 enero 2019 (RJ 146), $n^{\circ}$ 214/2019 5 abril 2019 (RJ 1360).
} 
El cambio de estas características que, bajo las premisas que establece la jurisprudencia, podría generar un supuesto de aplicación de la regla de la rebus sic stantibus es más probable que se dé en un contrato de larga duración, ordinariamente de tracto sucesivo. Pero no en un supuesto, como el presente, de contrato de corta duración, en el que difícilmente puede acaecer algo extraordinario que afecte a la base del contrato y no quede amparado dentro del riesgo propio de ese contrato.

Sin embargo, desde nuestra perspectiva, entendemos que cabe recurrir a la misma con independencia del contrato de que se trate, pues los perjuicios que se derivan pueden predicarse en todos los negocios jurídicos ${ }^{21}$. En el contexto de la pandemia generada por el COVID-19, consideramos que existen presupuestos más que suficientes para que se recurra a esta cláusula. Las pésimas consecuencias producidas no podían ser, de ningún punto, previsibles para los contratantes. Con base en la misma, se podría justificar tanto la modificación de un negocio jurídico como su rescisión. Máxime cuando se deriva una imposibilidad sobrevenida 22 para ejecutar los servicios o entregar los bienes pactados. Igualmente, no supondría una contradicción del principio pacta sunt servanda, sino una excepción al mismo ${ }^{23} \mathrm{o}$, si se quiere, un mecanismo complementario al régimen general. A modo de ejemplo, podríamos encontrarnos ante un caso en el que la prestación sanitaris no pueda cumplirse adecuadamente por el excesivo gasto que supone la obtención de las pruebas de detección del virus, por el propio tratamiento o, por ejemplo, por la necesidad de incorporar personal especializado. Como se observa, a pesar de que el campo de aplicación de esta excepción se ha vinculado, fundamentalmente, al sector patrimonial, ello no ha de ser así necesariamente.

En esta línea, parte de la doctrina ha destacado la viabilidad de su aplicación. Así, MAGRO SERVET ${ }^{24}$ vincula estas causas a la fuerza mayor al destacar que:

La operatividad de estas circunstancias se plasma como una causa de fuerza mayor, pero, sobre todo, con las características de imprevisible e inesperada que vienen a modificar las circunstancias iniciales del contrato y que atempera y modula esos incumplimientos por razón de las circunstancias sobrevenidas.

Además, el citado autor indica que, en esta situación del virus, concurren una serie de circunstancias que justificarian dicha posibilidad ${ }^{25}$. En este sentido, señala que, por un lado, la

${ }^{21}$ En esta línea, ORDUÑA MORENO, Francisco Javier. Cláusula Rebus. STS 156/2020, de 6 de marzo. Distinción entre contratos de "larga y corta duración". Una clasificación carente de rango o de categorización aplicativa: inoportuna y fuera de contexto social. Revista de Derecho vLex. n 191, 2020.

22 Para más información, vid. CLARIZIA, Oriana. Coronavirus ed esonero da responsabilità per inadempimento di obbligazione ex art. 1218 c.c.: impossibilità sopravvenuta oppure inesigibilità della prestazione?. AJI. no 12 bis, p. 352-365, may. 2020.

${ }^{23}$ En este sentido, destaca ALBIÑANA CILVETI, Ignacio. La reciente doctrina jurisprudencial de la cláusula rebus sic stantibus y su aplicación a las operaciones inmobiliarias. Actualidad Jurídica Uría Menéndez. $\mathrm{n}^{\circ}$ 49, p.116, 2018, que «La cláusula rebus supone una flexibilización y factor mitigador del rigor del principio pacta sunt servanda, en virtud del cual el contrato es fuente de obligaciones que han de cumplirse con arreglo a lo convenido».

${ }^{24}$ En este sentido, vid. MAGRO SERVET, Vicente. La crisis del coronavirus y la aplicación de las cláusulas "rebus sic stantibus" en los contratos. El Derecho, disponible en: https://elderecho.com/la-crisis-delcoronavirus-la-aplicacion-las-clausulas-rebus-sic-stantibus-los-contratos (fecha de última consulta: 04.05.2020).

${ }^{25}$ Así, destaca el citado autor que «En este caso concurre en la pandemia una circunstancia:

a.- Ajena a lo pactado. 
aplicación de la cláusula, en rigor, «no supone una ruptura o singularidad respecto de la regla preferente de la lealtad a la palabra dada (pacta sunt servanda), ni tampoco de la estabilidad o mantenimiento de los contratos». Por otro lado, destaca que:

2.- Esto quiere decir que en estos casos de pandemia no quiere decirse que la aplicación de la "Rebus" suponga romper el "pacta sunt servanda", porque quien queda afectado por el virus en su relación con lo pactado quería cumplirlo, pero la imprevisibilidad y ajenidad de la pandemia le impide hacerlo, o, al menos, en la manera como se pactó.

3.- Cuando, fuera de lo pactado y sin culpa de las partes y de forma sobrevenida, las circunstancias que dotaron de sentido la base o finalidad del contrato cambian profundamente, las pretensiones de las partes, lo que conforme al principio de buena fe cabe esperar en este contexto, pueden ser objeto de adaptación o revisión de acuerdo al cambio operado.

No obstante, tampoco es una cuestión pacífica en la doctrina científica y existen voces contrarias a la cláusula. Así, algunos autores ${ }^{26}$ advierten del riesgo de la expansión de esta regla en la jurisprudencia del Tribunal Supremo. En palabras de los citados autores.

Una aplicación de la regla rebus sic stantibus tan extensiva como la comentada podría llevar a efectos indeseados en el tráfico jurídico y económico, en la medida en que, a nuestro juicio, conlleva una falta de consideración a la distribución de riesgos contractuales y, en definitiva, a la voluntad de las partes, y genera una evidente inseguridad jurídica.

Por otro lado, en el ámbito extracontractual ${ }^{27}$ encontramos distintos supuestos de exoneración o moderación de la responsabilidad: a los ya mencionados casos de fuerza mayor y caso fortuito, cabe anudar aquellos de intervención de un tercero, de culpa exclusiva de la víctima e, incluso, de legítima defensa o estado de necesidad. A los efectos de esta investigación, solamente son relevantes los escenarios de fuerza mayor o caso fortuito, para lo que remitimos, mutatis mutandi, a lo destacado anteriormente. En el campo del Derecho de

b.-No hay culpa del afectado por la pandemia de coronavirus.

c.- Resulta de forma sobrevenida e inesperada.

d.- No era un riesgo previsible. No se podría prever.

e.- La incidencia de los efectos del virus es relevante y grave.

f.- Se manifiesta con una inusitada beligerancia en la imposibilidad de cumplir el contrato conforme a lo pactado.

g.- El principio de buena fe determina que el afectado por el virus actuó de buena fe y no colaboró en la imposibilidad de cumplir conforme a lo pactado.

h.- Esta relación entre el principio de buena fe y la cláusula rebus sic stantibus ya ha sido reconocida por el TS caso, entre otras, de la Sentencia de 21 de mayo de 2009 (núm. 1178/2004)».

${ }^{26}$ LUNA YERGA, Álvaro/XIOL BARDAJí, María. Rebus sic stantibus: ¿Un paso atrás? Comentario a la STS, $1^{\text {a }}, 15.10 .2014$ (Ar. 6129) y a la jurisprudencia posterior de la Sala Primera del Tribunal Supremo sobre la regla rebus sic stantibus. InDret. $\mathrm{n}^{\circ} 2$, p. 8, 2015.

${ }^{27}$ Para más información, vid. PEREIRA BONNA, Alexandre. Direito de danos, políticas públicas e a covid19: a pandemia que exige um novo conceito de responsabilidade civil. In: RÊGO MONTEIRO FILHO, Carlos Edison Do/ROSENVALD, Nelson/DENSA, Roberta (coord.). Coronavírus e responsabilidade civil: impactos contratuais e extracontratuais. Brasil: Editora Foco, SP, 2020, p. 249-262; LEONARDO CÂMARA CARRÁ, Bruno/OLIVEIRA LEMOS, Lívia. Coronavírus, direito à saúde e danos extrapatrimoniais: qual a correlação? In: RÊGO MONTEIRO FILHO, Carlos Edison Do/ROSENVALD, Nelson/DENSA, Roberta (coord.). Coronavírus e responsabilidade civil: impactos contratuais e extracontratuais. Brasil: Editora Foco, SP, 2020, p. 313-324. 
daños, con la aplicación de estos mecanismos, se interrumpe el nexo causal ${ }^{28}$. Esto se debe a que de alguna forma se integran en la acción, de tal forma que modifican, entre otras cuestiones, la causa o la finalidad que llevan a que el sujeto actúe de la forma en que lo ha hecho.

Además, cabe recordar lo que indicamos acerca del estado de la ciencia, ya que no existirá culpa o negligencia si no era posible conocer los extremos necesarios. En este ámbito, esto último pasa por la ausencia de criterios para saber la existencia del COVID-19, así como sus consecuencias y propagación. De alguna forma, las obligaciones que surgen en el sector extracontractual tienen origen legal al derivar de conductas ilícitas o socialmente reprochables. Sin embargo, al igual que con la aplicación de la cláusula rebus sic stantibus a los contratos, las imprevisibles circunstancias del virus pueden dar lugar a que se declare la ausencia o la limitación de la responsabilidad.

En este sentido, consideramos esencial determinar el estado de la ciencia del momento de producción de los hechos. Así, entendemos que no puede hacerse responsable al profesional si, conforme a los conocimientos científicos del momento es imposible detectar y, por tanto, informar acerca de una cuestión concreta. No existe una conducta alternativa posible, pues nadie hubiese actuado de otro modo y, por tanto, no estamos ante un hecho resarcible. De alguna forma, no es un acto negligente o reprochable a su autor, pues, en realidad, nadie en su situación podría haber actuado de otro modo. Para analizar la lex artis profesional se hace necesario reparar en los avances y el desarrollo de la medicina.

\section{PRINCIPALES CONCLUSIONES}

De todo lo visto hasta el momento, podemos extraer una serie de ideas. Por un lado, que en el ámbito profesional sanitario se hace necesario atender a la ley del oficio, que está formada por el conjunto de protocolos de actuación recomendados por la comunidad científica. No obstante, en este estudio, adquiere especial relevancia el estado de la ciencia del momento de producción de los hechos, pues el mismo representa el conocimiento que se maneja en dicha situación. No puede, por tanto, exigirse una conducta alternativa porque, sencillamente, no era posible llevarla a cabo. De hecho, si el médico se separa, unilateralmente, de dichas indicaciones podría estar ejecutando una acción contraria a la lex artis, al juramento hipocrático y a la propia deontología de la profesión.

$\mathrm{Si}$ atendemos a las peculiares circunstancias producidas por la propagación del COVID-19 y sus negativas consecuencias, podemos concluir que, en la actualidad, los avances no son suficientes y que, por tanto, el estado de la ciencia no ha alcanzado un estadio adecuado. Desde esta perspectiva, no parece correcto reprochar ciertas conductas de los sanitarios cuando estaban fundadas en el entendimiento del virus que se manejaba al ejecutarlas. Igualmente, hemos señalado aquellos supuestos que se pueden producir en la práctica (como, de hecho, así ha ocurrido) y que podrían quedar bajo el amparo de las anteriores reflexiones. En esencia, se

${ }^{28}$ Podemos destacar las SSTS no 112/2003 12 febrero 2003 (RJ 1010), n 154/2009 5 marzo 2009 (RJ 2792) que aplican estos criterios. 
trata de casos en los que, a pesar de que la conducta no es totalmente diligente desde una perspectiva ex post, no resulta justo exigir responsabilidad.

Por último, hemos analizado algunas de las herramientas previstas en el ordenamiento jurídico español a las que cabe recurrir en este campo, tanto en el ámbito contractual como extracontractual. Así, entre otras, encontramos la fuerza mayor, el caso fortuito o el cambio sobrevenido de las circunstancias. En este último supuesto, cobra especial relevancia la cláusula rebus sic stantibus, que ha sido vinculada por algún autor a la fuerza mayor. En suma, se trata de la producción de hechos de forma imprevisible e inesperada que modifican las cuestiones que fueron tenidas en cuenta a la hora de celebrar el negocio jurídico. Su efecto es, por tanto, atemperar la responsabilidad de dichos incumplimientos.

\section{REFERENCIAS}

ALBIÑANA CILVETI, Ignacio. La reciente doctrina jurisprudencial de la cláusula rebus sic stantibus y su aplicación a las operaciones inmobiliarias. Actualidad Jurídica Uría Menéndez. $\mathrm{n}^{\circ}$ 49, p.116, 2018.

ALVENTOSA DEL RÍO, Josefina. Salud y Derecho en tiempos del COVID-19. AJl. $\mathrm{n}^{\circ} 12$ bis, $\mathrm{p}$. 117, may. 2020.

BARCELÓ DOMÉNECH, Javier. Consentimiento informado y responsabilidad médica. AJI. $\mathrm{n}^{\circ} 8$, p. 279-296, feb. 2018.

BLAS ORBÁN, Carmen. Contagio transfusional de VHC. Reflexiones sobre la previsibilidad del daño. DS. v. 16/2008, p.181-182, 2008.

CLARIZIA, Oriana. Coronavirus ed esonero da responsabilità per inadempimento di obbligazione ex art. 1218 c.c.: impossibilità sopravvenuta oppure inesigibilità della prestazione? AJI. $\mathrm{n}^{\circ} 12$ bis, p. 352-365, may. 2020.

DA GUIA SILVA, Rodrigo/NOGAROLI, Rafaella. Utilização da inteligência artificial na análise diagnóstica da COVID-19: benefícios, riscos e repercussões sobre a responsabilidade civil do médico. In: RÊGO MONTEIRO FILHO, Carlos Edison Do/ROSENVALT, Nelson/DENSA, Roberta (coord.). Coronavirus e responsabilidade civil: impactos contratuais e extracontratuais. Brasil: Editora Foco, SP, 2020, p. 293-300.

DE LAS HERAS GARCÍA, Manuel Ángel. Lex Artis, Onus Probandi y responsabilidad médica. Revista jurídica de la Región de Murcia. n 36, p. 17-19, 2005.

DE OLIVEIRA MILAGRES, Marcelo. Os efeitos do coronavírus (covid-19) e a irreversibilidade não imputável do incumprimento contratual. In: RÊGO MONTEIRO FILHO, Carlos Edison Do/ROSENVALT, Nelson/DENSA, Roberta (coord.). Coronavirus e responsabilidade civil: impactos contratuais e extracontratuais. Brasil: Editora Foco, SP, 2020, p. 47-54.

GIOVA, Stefania. Infezione da COVID-19 e responsabilità della struttura sanitaria. AJI. $\mathrm{n}^{\circ} 12$ bis, p. 502-511, may. 2020.

GÓMEZ ABEJA, Laura. Consentimiento informado y derechos fundamentales. Revista Europea de Derechos Fundamentales. n 18, p. 275-306, 2011.

GUINOT BARONA, María. La responsabilidad extracontractual. In: Manual sobre Responsabilidad Sanitaria. Navarra: Aranzadi, 2009, p. 421. 
KOURY GONZÁLEZ, Juan Miguel/HIRSCHHAUT, Miguel. Reseña histórica del COVID-19. ¿Cómo y por qué llegamos a esta pandemia? Acta odontológica venezolana. v. 58/2020, p. 3 , 2020.

LEONARDO CÂMARA CARRÁ, Bruno/OLIVEIRA LEMOS, Lívia. Coronavírus, direito à saúde e danos extrapatrimoniais: qual a correlação? In: RÊGO MONTEIRO FILHO, Carlos Edison Do/ROSENVALT, Nelson/DENSA, Roberta (coord.). Coronavírus e responsabilidade civil: impactos contratuais e extracontratuais. Brasil: Editora Foco, SP, 2020, p. 313-324.

LUNA YERGA, Álvaro/XIOL BARDAJÍ, María. Rebus sic stantibus: ¿Un paso atrás? Comentario a la STS, $1^{\text {a }}, 15.10 .2014$ (Ar. 6129) y a la jurisprudencia posterior de la Sala Primera del Tribunal Supremo sobre la regla rebus sic stantibus. InDret. $n^{\circ} 2$, p. 8, 2015.

MAGRO SERVET, Vicente. La crisis del coronavirus y la aplicación de las cláusulas "rebus sic stantibus" en los contratos. El Derecho, disponible en: https://elderecho.com/la-crisis-delcoronavirus-la-aplicacion-las-clausulas-rebus-sic-stantibus-los-contratos (fecha de última consulta: 04.05 .2020$)$.

MUGA MUÑOZ, José Luis. La responsabilidad patrimonial de las administraciones públicas por el contagio de sida. RAP. $\mathrm{n}^{\circ} 136$, p. 287, 1995.

ORDUÑA MORENO, Francisco Javier. Webinar COVID-19: La rebus en tiempos de crisis. vLex. $\mathrm{n}^{\circ}$ 2020, disponible en: https://libros-revistas-derecho.vlex.es (fecha de última consulta 08.05.2020).

ORDUÑA MORENO, Francisco Javier. Cláusula Rebus. STS 156/2020, de 6 de marzo. Distinción entre contratos de "larga y corta duración". Una clasificación carente de rango o de categorización aplicativa: inoportuna y fuera de contexto social. Revista de Derecho vLex. $\mathrm{n}^{\circ}$ 191, 2020.

ORDUÑA MORENO, Francisco Javier/MARTÍNEZ VELENCOSO, Luz María. La moderna configuración de la cláusula Rebus Sic Stantibus. Desarrollo de la nueva doctrina jurisprudencial aplicable y Derecho comparado. Madrid: Civitas, 2017.

PEREIRA BONNA, Alexandre. Direito de danos, políticas públicas e a covid-19: a pandemia que exige um novo conceito de responsabilidade civil. In: RÊGO MONTEIRO FILHO, Carlos Edison Do/ROSENVALT, Nelson/DENSA, Roberta (coord.). Coronavírus e responsabilidade civil: impactos contratuais e extracontratuais. Brasil: Editora Foco, SP, 2020, p. 249-262.

RAMOS, Celso. Covid-19: la nueva enfermedad causada por un coronavirus. Salud pública de México. v. 62/2020, p. 226, 2020.

ROSENVALD, Nelson. Responsabilidade civil na área médica. AJI. n 8, p. 373-420, feb. 2018.

Recebido: 29.06 .2020

Aprovado: 09.07.2020

Como citar: ORTIZ FERNÁNDEZ, Manuel. Algunos apuntes sobre la responsabilidad civil sanitaria ante la situación generada por el Covid-19. Revista IBERC, Belo Horizonte, v. 3, n. 2, p. 289-304, maio/ago. 2020.

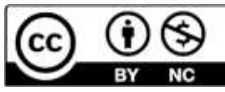

